\section{Evolución espacio-temporal de relictos de humedal: el caso del sector de Villa Baja del Sitio Ramsar Los Pantanos de Villa (2003-2019)}

Jorge Campos-Macedo ${ }^{1 *}$, Josselin Huachaca ${ }^{\circledR}$ y Paulo Morales ${ }^{2}{ }^{\circ}$
Spatial and temporal evolution of relict wetlands in the Villa Baja sector of Los Pantanos de Villa Ramsar site (2003-2019)

\footnotetext{
1 Universidad Científica del Sur. Lima, Perú.

2 Universidad Nacional Mayor de San Marcos. Lima, Perú.
}

\section{SOUTH} SUSTAINABILITY

Citar como: Campos-Macedo, l. et al. (2022). «Evolución espacio-temporal de relictos de humedal: el caso del sector de Villa Baja del Sitio Ramsar Los Pantanos de Villa (2003-2019)». South Sustainability, 2(2), e037. DOI: 10.21142/SS-0202-2021-ac001

Artículo recibido: 7/10/2021 Revisado por pares

Artículo aprobado: 31/12/2021

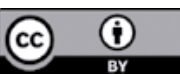

(c) Los autores, 2021. Publicado por la Universidad Científica del Sur (Lima, Perú)

${ }^{*}$ E-mail de correspondencia: camposmacedojorge@gmail.com

\section{RESUMEN}

La zona de amortiguamiento del Refugio de Vida Silvestre Los Pantanos de Villa (RVSPV) permite establecer un área de transición entre el humedal y la zona urbana. En los últimos años existieron cambios de uso de suelo en este sector, los cuales no han sido cuantificados. El objetivo de la presente investigación fue evaluar la evolución espacio-temporal de los relictos de humedal y la urbanización en la zona de amortiguamiento en el sector de Villa Baja de 2003 a 2019. Para ello, se realizó un análisis de las edificaciones y la extensión vegetal en esta zona en los años 2003, 2010, 2015 y 2019; se utilizaron imágenes satelitales de Google Earth y una clasificación supervisada de las áreas; finalmente, se construyeron mapas en ArcGIS. Los resultados obtenidos muestran un aumento de 21,31 ha en las edificaciones; la vegetación natural disminuyó en 15,01 ha (que representa una reducción del $52,7 \%$ ) en 16 años. Si esta tasa de reducción se mantiene, para 2031 podríamos no contar con áreas de vegetación natural en este sector del humedal. La reducción identificada se encuentra íntimamente ligada a las actividades humanas que se desarrollan en el área.

Palabras clave: actividades antropogénicas, humedal costero, Los Pantanos de Villa, relicto de humedal, sitio Ramsar, zona de amortiguamiento

\section{ABSTRACT}

The buffer zone of Los Pantanos de Villa Wildlife Refuge (RVSPV) constitutes a transition zone between the wetland and the urban area. In recent years, there have been changes in land use within this sector, and these have not been quantified. The aim of this research was to evaluate the spatial and temporal evolution of the relict wetlands and urbanization in the buffer zone (Villa Baja sector) from 2003 to 2019. To this end, an analysis of the buildings and the extent of vegetation cover in this zone in 2003, 2010, 2015 and 2019 was conducted. Google Earth satellite images were used, followed by supervised classification of the areas. Finally, ArcGIS maps were constructed. The results obtained show an increase of 21.31 ha in buildings, while natural vegetation decreased by 15.01 ha (representing a reduction of $52.7 \%$ ), over 16 years. If this rate of decrease is maintained, by the year 2031 there may no longer be any areas of natural vegetation in this wetland sector. The reduction identified is closely associated with human activities in the area.

Keywords: Anthropogenic activities, coastal wetland, Los Pantanos de Villa, relict wetland, Ramsar site, buffer zone 


\section{Introducción}

Los humedales se definen como extensiones pantanosas, turberas, marismas, en las cuales se presentan superficies cubiertas de agua, ya sean artificiales o de régimen natural, dulces, saladas, temporales o permanentes. Por la gran complejidad que presentan, muchas veces es difícil asignarlos en una determinada categoría (Frazier, 1999). La Convención Ramsar asigna sitios específicos en el mundo para su uso adecuado. Asimismo, organiza y provee una serie de mecanismos flexibles para el cuidado del sitio con ayuda del gobierno. Uno de los principales enfoques para la selección de sitios Ramsar son las zonas que poseen importancia fundamental para las aves migratorias; sin estos ecosistemas, las aves no podrían seguir con su ciclo de vida. Se proyecta que, en el futuro, la prioridad debe ser brindar la atención correspondiente a todas las partes que influyen en la administración de los sitios Ramsar, para que respondan eficientemente a las rápidas consecuencias generadas por el cambio climático (Gardner y Davidson, 2011). De igual manera, la conservación de los distintos tipos de humedales, entre ellos los costeros, también contribuye a la reducción de los diferentes impactos humanos, como los efectos provenientes del cambio climático (Sulca, 2020).

El Perú cuenta con un número significativo de humedales, que abarcan aproximadamente 8 millones de ha; de ellos, 13 humedales han sido incluidos dentro de la Convención Ramsar (Flores et al., 2020). Los humedales del departamento de Lima forman parte de un corredor biológico de toda la costa peruana, en los cuales se han realizado múltiples estudios de flora y fauna (Aponte y Ramirez, 2011). A esto se le añade que los humedales nos proveen de una serie de servicios ecosistémicos como el almacenamiento de carbono (Ampuero y Aponte, 2020). Los Pantanos de Villa se ubican en el desierto costero en el sur de la ciudad de Lima, en la antigua carretera de la Panamericana Sur, entre los kilómetros 18 y 21. Se crearon a partir de las aguas subterráneas del río Surco, y cuentan con grandes elementos biogeográficos y endemismos que los hicieron catalogar como un sitio de importancia internacional Ramsar (Pulido y Bermudez, 2018).

La administración y gestión de los Pantanos de Villa, según la Ley de Áreas Naturales Protegidas, Ley 26834, es responsabilidad directa del Servicio Nacional de Áreas Naturales Protegidas (Sernanp) y del organismo descentralizado de la Municipalidad de Lima con competencia municipal Prohvilla, según la Ordenanza 1845-2014-MMI. Ambas instituciones tienen como función fomentar la conservación de este sitio Ramsar, incluyendo la diversidad biológica, los recursos naturales y las actividades encargadas de promover el desarrollo sostenible (Sulca, 2020).

Los humedales, ubicados en el interior del casco urbano de las ciudades, como los Pantanos de Villa y su área de amortiguamiento que incluye los relictos de humedal, adquieren importancia para la vida silvestre y las poblaciones humanas, porque cumplen funciones como la regulación de los regímenes hidrológicos, áreas para el desarrollo de la educación ambiental, el disfrute, el esparcimiento y la provisión de recursos para las comunidades locales (Pulido et al., 2020). La continuidad de los servicios ecosistémicos están ligados a los relictos de humedal del sector de Villa Baja a causa de la ubicación de puquiales y canales que alimentan el humedal de los Pantanos de Villa (figura 1).

No obstante, las interrelaciones hombre-naturaleza no siempre son positivas. Entre los impactos directos que afectan a los humedales, tenemos el crecimiento urbanístico, que avasalla de manera importante estos espacios naturales, así como la acumulación de escombros o basura, y el manejo inadecuado de la ganadería o la agricultura (Aponte et al., 2020). Este impacto se refleja en el aumento de zonas sin vegetación mostrada en la investigación de Flores et al. (2020), que concluye que los Pantanos de Villa han sufrido una pérdida de las áreas vegetales en un $17 \%$ entre 2008 y 2018, y que el gramadal fue la unidad de vegetación de mayor reducción. Ante esta situación, el objetivo de este artículo fue evaluar la evolución espacio-temporal de 2003 a 2019 de los relictos de humedal y la urbanización en el sector de Villa Baja, ubicado en la zona de amortiguamiento del sitio Ramsar Los Pantanos de Villa.

\section{Métodos}

La metodología empleada se basó en la aplicación de la percepción remota o teledetección y sistemas de información geográfica, y utilizó el análisis espaciotemporal mediante imágenes satelitales de Google Earth de 2003, 2010, 2015 y 2019 para la zona de Villa Baja. Este sector se ubica en el área de amortiguamiento de los Pantanos de Villa (figura 1). Aquí se delimitó el área construida y la extensión del área de relictos de humedal que quedaban en ese lugar, para así determinar si existe una relación causal entre el aumento del área construida y el área de los relictos de humedales. Se realizó también trabajo de campo para anotar in situ las diferentes actividades antropogénicas que atentan contra la conservación y preservación de los relictos de humedal. Finalmente, se elaboró una proyección del posible peor escenario a futuro del sector Villa Baja, teniendo en cuenta la tendencia actual del aumento del área construida y la disminución del área vegetal natural de humedal. Para esto fue necesario hallar la tasa de crecimiento anual, con la cual se realizó esta proyección hasta 2031, debido a que en este año el área vegetal natural de humedal daba como cifra cero. Este fue un método similar al aplicado por Sánchez en su investigación sobre los cambios en la cobertura vegetal en el humedal Toqui-Toqui en Colombia. 


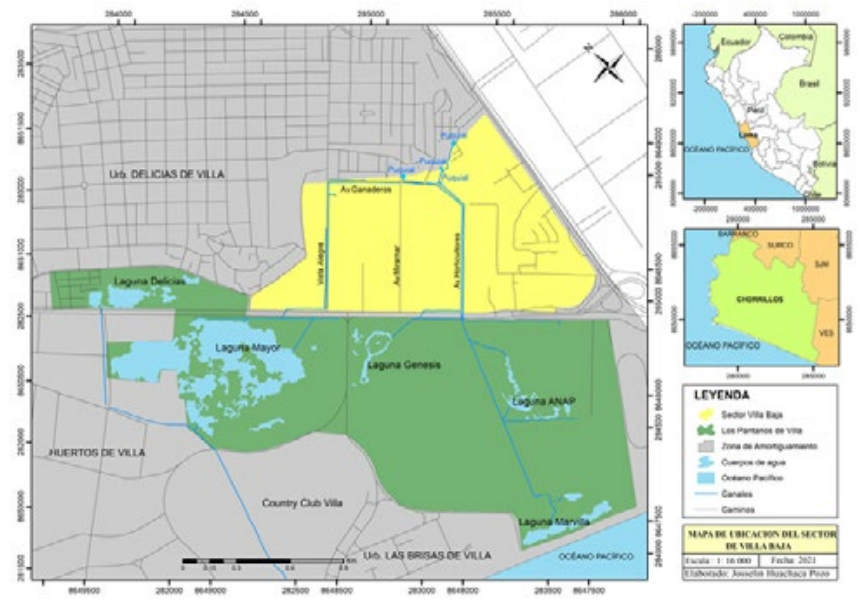

Figura 1. Mapa de ubicación del área de estudio (zona marcada en amarillo).

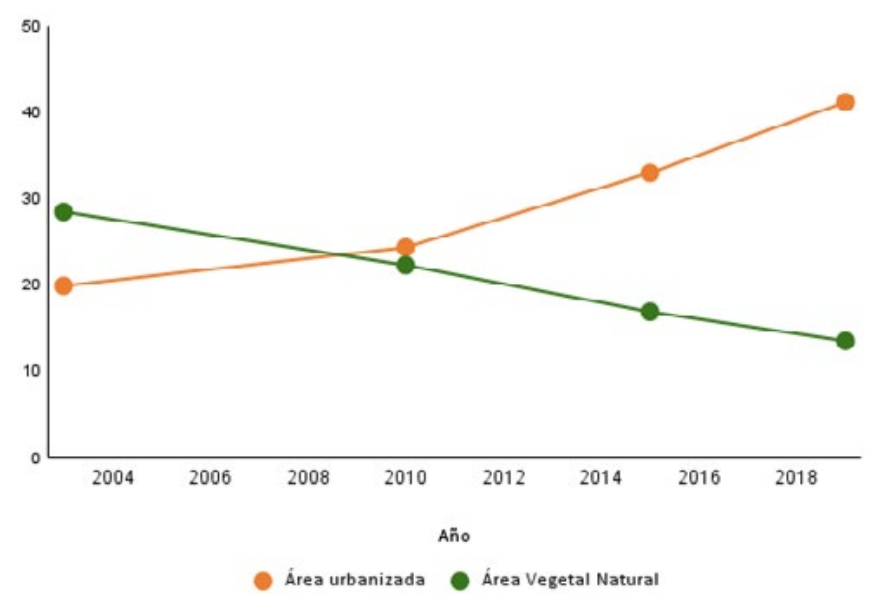

Figura 2. Evolución espacio-temporal de la zona urbanizada (línea punteada) y los relictos de humedal (sólida) del área de estudio. El eje Y indica la extensión en hectáreas.
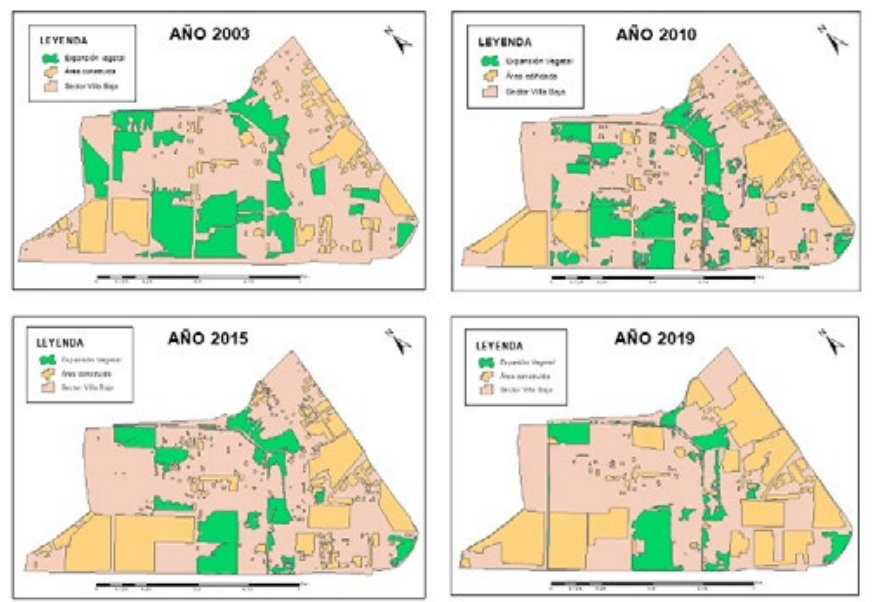

Figura 3. Mapas del sector de Villa Baja mostrando la evolución espaciotemporal en 2003, 2010, 2015 y 2019.

\section{Resultados}

Los resultados muestran que la zona de Villa Baja en la actualidad cuenta con un área total de 127,49 ha. En este sector el crecimiento urbanístico ha ido aumentando de manera exponencial de 2003 a 2019, con un total de 20,53 ha; durante este periodo el área de relicto de humedal pasó de tener 28,51 ha a 13,50 ha: se redujo en un $52,7 \%$ en 16 años (figuras 2 y 3 ).

Las áreas que han tenido mayor disminución en la extensión de relicto de humedal corresponden a un grupo de almacenes, donde incluso en los primeros años de estudio había una pequeña laguna. Cerca de este lugar, colindante a la avenida Vista Alegre, se puede notar que el área de humedal aledaña a los campos agrícolas también se ha reducido notablemente. Se ve afectada toda la zona correspondiente a la avenida Horticultores y el inicio de la avenida Ganaderos, donde hoy podemos encontrar la presencia de empresas radiales.

Según el análisis realizado podemos percibir que en 2019 la zona urbana tenía 41,22 ha, mientras que la zona relicto de humedal cuenta con 13,5 ha. En caso la tendencia se mantenga, para 2031 ya no contaremos con más extensión de relicto de humedal en la zona de Villa Baja; cabe recalcar que para entonces 90 ha de las 127 ha ya estarían construidas (figura 4). Mediante las visitas de campo realizadas al área de estudio, se pudo constatar cómo las diferentes actividades antropogénicas han repercutido negativamente en la zona de amortiguamiento de los Pantanos de Villa. Entre ellas destacan la inadecuada disposición de residuos sólidos por parte de los pobladores (incluyendo desmontes de construcción, que son depositados de manera indiscriminada), la inexistencia de un ordenamiento territorial por las construcciones precarias inadecuadas que afectan directamente los canales principales, el estrés hídrico generado por el mal uso de las fuentes de agua, la degradación del suelo por el mal manejo del ganado vacuno y quema de pastizales, entre otras.

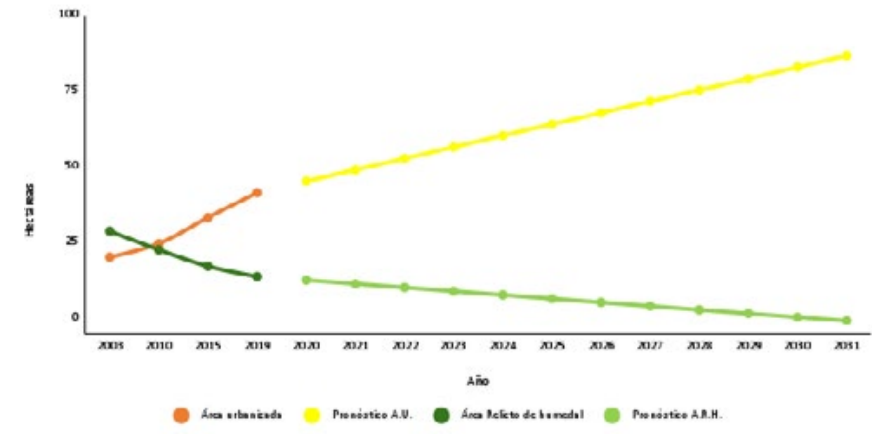

Figura 4. Evolución espacio-temporal hipotética tendencial de la zona urbanizada (líneas punteadas) y los humedales relictos (líneas sólida) del área de estudio. 


\section{Discusión}

Los humedales situados en la zona urbana de la ciudad de Lima vienen siendo avasallados por las construcciones, las cuales ocupan zonas en donde antes había presencia de humedales costeros. Ello conlleva al riesgo de desaparecer en un futuro no muy lejano, como se ha evidenciado en estudios de humedales urbanos en Chile (por ejemplo, Rojas et al., 2019). La inadecuada disposición de residuos sólidos en los alrededores de los Pantanos de Villa conlleva a que en muchos casos viviendas precarias terminen siendo construidas en lugares en donde había presencia vegetal natural. También ocasiona obstrucciones en el flujo de los canales que conectan directamente con el sitio Ramsar, y el uso incorrecto de las aguas naturales para lavado de vehículos y vertimientos de aguas grises. Todas estas inadecuadas actividades antropogénicas generan un riesgo para el RVSPV, debido a que en el sector de Villa se encuentran tres importantes manantiales que alimentan a este frágil ecosistema (Aponte et al., 2018).

Ante actividades amenazantes, la gestión del humedal es clave para la recuperación, protección y conservación de este ecosistema. Esta gestión se puede lograr a través de la recuperación legal de zonas colindantes al humedal, con la cooperación de los propietarios y las empresas colindantes, para la conservación y una correcta gestión ambiental, propiciando la participación de la comunidad local permanentemente y la difusión de la importancia de los humedales a través del turismo, y logrando sinergias entre los actores involucrados en la gestión; así lo señala Aponte (2017). Por ello, la gestión de los humedales y sus zonas de amortiguamiento determinarán el éxito de las estrategias y medidas que se desarrollen, porque el no garantizar el correcto funcionamiento del ecosistema puede conllevar una serie de repercusiones, principalmente de carácter ambiental, ecológico, social y económico.

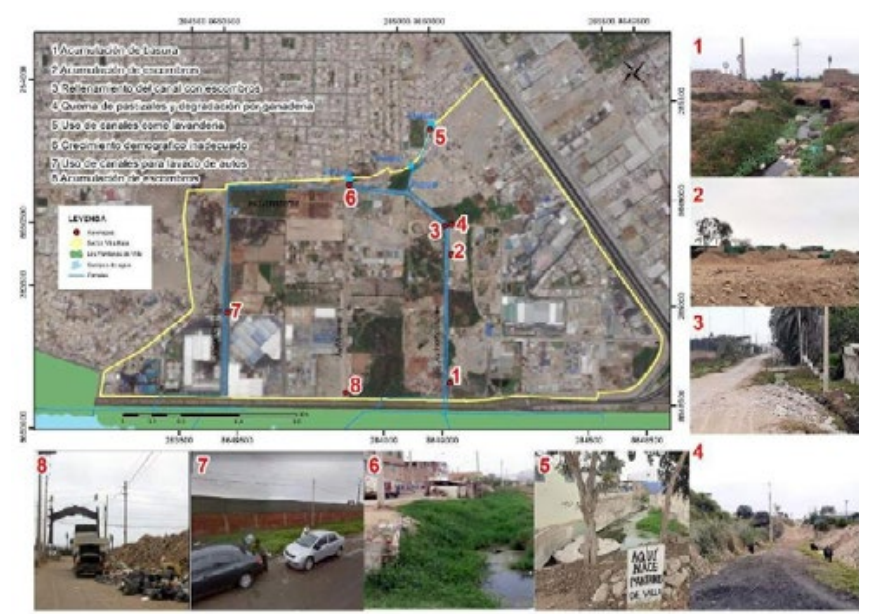

Figura 5. Mapa de amenazas antropogénicas.

\section{Agradecimientos}

Se agradece a la Universidad Científica del Sur y a la Autoridad Municipal de los Pantanos de Villa (Prohvilla) por el apoyo brindado durante el proceso de creación de este artículo.

\section{Contribución de autoría}

Los tres autores de este artículo contribuyeron de manera equitativa y eficiente.

\section{Fuente de financiamiento}

Prohvilla.

\section{Potenciales conflictos de interés}

Ninguno.

\section{Referencias bibliográficas}

Ampuero, W. y Aponte, H. (2020). «Estimación del carbono almacenado en un juncal de Schoenoplectus americanus en el humedal costero Los Pantanos de Villa (Lima, Perú)». Arnaldoa, 27(1), pp. 267-281.

Aponte, H., Gonzales, S. y Gomez, A. (2020). «Impulsores de cambio en los humedales de América Latina: El caso de los humedales costeros de Lima». South Sustainability, 1(2), e023-e023.

Aponte, H., Ramírez, D. y Lértora, G. (2018). Los Pantanos de Villa. Un oasis de vida en Lima Metropolitana. Fondo Editorial de la Universidad Científica del Sur.

Aponte, H. (2017). Humedales de la Costa central del Perú. Un diagnóstico de los humedales de Santa Rosa, laguna El Paraíso y Albufera de Medio Mundo. CooperaciAcción.

Aponte Ubillús, H. y Ramírez Huaroto, D. W. (2011). «Humedales de la costa central del Perú: Estructura y amenazas de sus comunidades vegetales». Ecología Aplicada, 10(1), pp. 31-39.

Flores, N., Castro, I. y Aponte, H. (2020). «Evaluación de las unidades de vegetación en Los Pantanos de Villa (Lima, Perú) mediante sistemas de información geográfica y teledetección». Arnaldoa, 27(1), pp. 303-321.

Frazier, S. (1999). Visión general de los sitios Ramsar. Una sinopsis de los humedales de importancia internacional en el mundo. Wetlands International.

Gardner, R. C. y Davidson, N. C. (2011). The Ramsar Convention. En: Wetlands (pp. 189-203). Springer.

Pulido Capurro, V. M. y Bermúdez Díaz, L. (2018). «Estado actual de la conservación de los hábitats de los Pantanos de Villa, Lima, Perú». Arnaldoa, 25(2), pp. 679-702.

Pulido, V., Salinas, L., Del Pino, J. y Arana, C. (2020). «Preferencia de hábitats y estacionalidad de las especies de aves de los Pantanos de Villa en Lima, Perú». Revista Peruana de Biología, 27(3), pp. 349-360.

Ramirez, D., Aponte, H., Lertora, G. y Gil, F. (2018). «Incendios en el humedal Ramsar Los Pantanos de Villa (Lima-Perú): Avances en su conocimiento y perspectivas futuras». Revista de Investigaciones Altoandinas, 20(3), pp. 347-360.

Rojas, C., Munizaga, J., Rojas, O., Martínez, C. y Pino, J. (2019). «Urban development versus wetland loss in a coastal Latin American city: Lessons for sustainable land use planning». Land use Policy, 80, pp. 47-56. 
Rojas, C., Aldana-Dominguez, J., Munizaga, J., Moschella, P., Martínez, C., Stamm, C. (2020). «Urban wetland trends in three Latin American cities during the latest decades (2002-2019): Concón (Chile), Barranquilla (Colombia), and Lima (Perú)». Wetlands Science \& Practice, 37(4), pp. 283-293.

Sánchez, N. (2018). Cambios en la cobertura vegetal y en el espejo de agua asociados a la influencia antrópica en el humedal Toqui-Toqui. Trabajo presentado para optar al título de magíster en Desarrollo Sostenible y Medio Ambiente. Universidad de Manizales.

Sulca, G. M. L. (2020). «Gobernanza ambiental y conservación: las gestiones del SERNANP y PROHVILLA en el Refugio de Vida Silvestre Los Pantanos de Villa». Revista Argumentos, 1(1), pp. 119-124.

Watson, J. E., Dudley, N., Segan, D. B. y Hockings, M. (2014). «The performance and potential of protected areas». Nature, 515(7525), pp. 67-73. 